\title{
Slowing down and taking a second look: Inhibitory deficits associated with binge eating are not food- specific
}

Citation for published version (APA):

Manasse, S. M., Goldstein, S. P., Wyckoff, E., Forman, E. M., Juarascio, A. S., Butryn, M. L., Ruocco, A. C., \& Nederkoorn, C. (2016). Slowing down and taking a second look: Inhibitory deficits associated with binge eating are not food-specific. Appetite, 96, 555-559. https://doi.org/10.1016/j.appet.2015.10.025

Document status and date:

Published: 01/01/2016

DOI:

10.1016/j.appet.2015.10.025

Document Version:

Publisher's PDF, also known as Version of record

\section{Document license:}

Taverne

Please check the document version of this publication:

- A submitted manuscript is the version of the article upon submission and before peer-review. There can be important differences between the submitted version and the official published version of record.

People interested in the research are advised to contact the author for the final version of the publication, or visit the DOI to the publisher's website.

- The final author version and the galley proof are versions of the publication after peer review.

- The final published version features the final layout of the paper including the volume, issue and page numbers.

Link to publication

\footnotetext{
General rights rights.

- You may freely distribute the URL identifying the publication in the public portal. please follow below link for the End User Agreement:

www.umlib.nl/taverne-license

Take down policy

If you believe that this document breaches copyright please contact us at:

repository@maastrichtuniversity.nl

providing details and we will investigate your claim.
}

Copyright and moral rights for the publications made accessible in the public portal are retained by the authors and/or other copyright owners and it is a condition of accessing publications that users recognise and abide by the legal requirements associated with these

- Users may download and print one copy of any publication from the public portal for the purpose of private study or research.

- You may not further distribute the material or use it for any profit-making activity or commercial gain

If the publication is distributed under the terms of Article $25 \mathrm{fa}$ of the Dutch Copyright Act, indicated by the "Taverne" license above, 


\title{
Slowing down and taking a second look: Inhibitory deficits associated with binge eating are not food-specific
}

\author{
Stephanie M. Manasse ${ }^{\text {a, }}$, Stephanie P. Goldstein ${ }^{a}$, Emily Wyckoff a, Evan M. Forman ${ }^{a}$, \\ Adrienne S. Juarascio a , Meghan L. Butryn ${ }^{a}$, Anthony C. Ruocco ${ }^{b}$, Chantal Nederkoorn ${ }^{c}$ \\ ${ }^{a}$ Drexel University, Department of Psychology, Philadelphia, PA, USA \\ ${ }^{\mathrm{b}}$ University of Toronto Scarborough, Department of Psychology, Toronto, Canada \\ ${ }^{\mathrm{c}}$ Maastricht University, Maastricht, Netherlands
}

\section{A R T I C L E I N F O}

\section{Article history:}

Received 2 August 2015

Received in revised form 25 September 2015

Accepted 22 October 2015

Available online 30 October 2015

\section{Keywords:}

Inhibitory control

Response inhibition

Stop signal task

Binge eating

Loss-of-control eating

\begin{abstract}
A B S T R A C T
Poor inhibitory control may contribute to the maintenance of binge eating (BE) among overweight and obese individuals. However, it is unknown whether deficits are general or specific to food (versus other attractive non-food stimuli), or whether observed deficits are attributable to increased depressive symptoms in BE groups. In the current study, we hypothesized that individuals with BE would display inhibitory control deficits, with more pronounced deficits occurring when food stimuli were used. Overweight or obese participants with $(n=25)$ and without $(n=65)$ BE completed a Stop Signal Task (SST) with distinct task blocks featuring food-specific stimuli, positive non-food stimuli, or neutral stimuli. The BE group exhibited poorer inhibitory control across SST stimuli types $\left(p=.003, \eta_{p}^{2}=.10\right)$, but deficits did not differ by stimuli type $\left(p=.68, \eta_{p}^{2}<.01\right)$. Including depression as a covariate did not significantly alter results. Results suggest individuals with BE display inhibitory control deficits compared to controls; however, deficits do not appear to be specific to stimuli type. Furthermore, inhibitory control deficits do not appear to be associated with mood disturbance in the BE group. Replication and further research is needed to guide treatment targets.
\end{abstract}

๑) 2015 Elsevier Ltd. All rights reserved.

\section{Introduction}

Obesity is a major public health problem associated with a myriad of poor long-term health outcomes (Danaei et al., 2009). Obese individuals who engage in binge eating (BE; i.e., eating a large amount of food in a discrete time period, driven by a sense of loss of control [LOC]) demonstrate even poorer long-term weight outcomes and overall quality of life than their non-binge eating counterparts (Wilfley, Wilson, \& Agras, 2003). Given that the majority of overweight or obese individuals do not endorse BE (Ricca et al., 2000), and that weight loss and long-term weight loss maintenance is particularly challenging for those with BE (Pagoto et al., 2007), understanding the distinct BE maintenance factors is crucial for developing tailored weight management interventions.

Reduced inhibitory control (i.e., the ability to withhold an automatic response) is one factor hypothesized to contribute to the

\footnotetext{
* Corresponding author. Department of Psychology, Drexel University, Stratton Hall, 3141 Chestnut Street, Suite 119, Philadelphia, 19104, PA, USA.

E-mail address: smm522@drexel.edu (S.M. Manasse).
}

development and maintenance of BE (Svaldi, Naumann, Trentowska, \& Schmitz, 2014a) above and beyond its role in general obesity (Grucza, Przybeck, \& Cloninger, 2007). Although deficits in inhibitory control have been found in those who are obese in the absence of BE (Smith, Hay, Campbell, \& Trollor, 2011), even greater inhibitory deficits are theorized to contribute to the compulsive nature of $\mathrm{BE}$, and the inability to stop eating once started (Balodis et al., 2013).

The extant literature on the presence of inhibitory control deficits in those with BE is somewhat mixed (Wu, Hartmann, Skunde, Herzog, \& Friederich, 2013), with four studies detecting differences between $\mathrm{BE}$ and overweight/obese control groups (Duchesne et al., 2010; Hege et al., 2015; Manasse et al., 2014; Mobbs, Iglesias, Golay, \& Van der Linden, 2011; Svaldi, Naumann, Trentowska, \& Schmitz, 2014b) and three studies failing to detect such differences (Kelly, Bulik, \& Mazzeo, 2013; Manasse et al., 2015; Wu, Giel, et al., 2013). One potential explanation for mixed findings is that several studies have used inhibitory control tasks that incorporate neutral stimuli (e.g., letters of the alphabet), but inhibitory deficits in those with BE may be especially pronounced when relevant 
stimuli are used, e.g., food (Svaldi et al., 2014b). Recent dual-process models of self-control posit that dysregulated behavior such as BE may occur via a combination of increased appetitive drive for a stimulus (e.g., food) and deficits in self-regulatory processes such as inhibitory control (Hofmann, Friese, \& Strack, 2009). Preliminary research has supported inhibitory control deficits to food-specific stimuli in overweight compared to healthy weight individuals (Houben, Nederkoorn, \& Jansen, 2014; Nederkoorn, Coelho, Guerrieri, Houben, \& Jansen, 2012). Moreover, differential responsivity to food stimuli has been detected in individuals with BE (Geliebter et al., 2006; Svaldi, Tuschen-Caffier, Peyk, \& Blechert, 2010). Thus, utilizing both food and non-food stimuli could allow examination of the effect of appetitive drive (e.g., via pictures of food) on inhibitory control.

To date, only one study has compared non-food and foodspecific inhibitory control in individuals with BE (Svaldi et al., 2014b), although another utilized a solely food-specific go/no-go paradigm (Hege et al., 2015). Both investigations detected foodspecific inhibitory control deficits in BE individuals. However, no studies have included food-specific, neutral, and positivelyvalenced non-food stimuli (e.g., sunsets) in the same task. Inclusion of the non-food stimuli blocks provides information regarding general inhibitory control deficits, and using positively-valenced non-food stimuli serves as a method of controlling for the "attractiveness" of food stimuli. In addition, the extant literature is inconsistent in terms of the facet of inhibitory control being measured (e.g., conflict monitoring using a Stroop task vs. latestage inhibition using a Stop Signal Task; SST). Given that hedonic drive, as described above, generates a strong automatic response, the most theoretically consistent form of inhibitory control to measure may be the ability to withhold an already-initiated motor response, as in the SST. Thus, utilizing all three stimuli in a SST may help specify whether response inhibition deficits in BE are limited to food-based, generally attractive, and/or neutral stimuli.

Another limitation of the extant literature is the lack of inclusion of relevant mediating variables in analyses. In particular, depressive symptoms, which are associated with poor inhibitory control (Kaiser et al., 2003), are often significantly elevated in individuals with BE (Grucza et al., 2007; Telch \& Stice, 1998). In one study, controlling for depressive symptoms essentially eliminated differences in inhibitory control (measured by a Stroop task) between BE and control groups (Manasse et al., 2015). It is possible that mood disturbance could differentially impact performance on tasks measuring information processing and monitoring as in the Stroop task (van Veen, Cohen, Botvinick, Stenger, \& Carter, 2001) and late stage motor inhibition (i.e., withholding an already initiated response) as in the SST. To extend current research on inhibitory control deficits among individuals with $\mathrm{BE}$, it is necessary to (1) compare inhibitory control performance of $\mathrm{BE}$ and overweight controls across stimulus types (non-food, positively valenced nonfood, food); and (2) control for depressive symptoms between groups.

\subsection{Current study}

In the current study, we sought to examine the main and interaction effects of BE status and type of stimuli used in a SST task on inhibitory control performance. We modified a standard SST to include three distinct stimulus types: food stimuli, positivelyvalenced non-food stimuli, and neutral stimuli. We hypothesized that the BE group would perform worse than the overweight control group (OWC) on all stimulus types of the SST, but that there would be a BE status $x$ SST stimulus type interaction such that the differences between groups would be most pronounced on the food stimuli of the SST. In addition, we also hypothesized that inhibitory control deficits in individuals with $\mathrm{BE}$ are not attributable to mood disturbance and thus that differences would persist when statistically controlling for depressive symptoms.

\section{Methods}

\subsection{Participants and procedure}

We included treatment-seeking overweight and obese $\left(\mathrm{BMI}=26-50 \mathrm{~kg} / \mathrm{m}^{2}\right)$ females who endorsed regular BE (BE group) and a group of overweight or obese women without any past or present BE (OWC group). Participants were recruited via treatment studies for weight loss or binge eating, and were assessed prior to receiving any treatment.

Participants in the OWC group ( $n=65)$ had no LOC eating episodes in the past 3 months and no current or past history of BE. Participants in the BE group $(n=25)$ endorsed at least 12 objectively or subjectively large binge episodes over the past 3 months, and did not meet criteria for bulimia nervosa. We included individuals with subjectively large binge episodes given evidence that neurocognitive factors (Manasse et al., 2014) and functional impairment associated with $\mathrm{BE}$ is most associated with presence of LOC, not size of binge episodes (Latner, Hildebrandt, Rosewall, Chisholm, \& Hayashi, 2007; Mond et al., 2006).

\subsection{Measures}

\subsubsection{Binge eating}

The Eating Disorders Examination (EDE) is the gold-standard semi-structured interview for assessing for BE (Grilo, Masheb, Lozano-Blanco, \& Barry, 2004; Wilfley, Schwartz, Spurrell, \& Fairburn, 1997). The Overeating section was administered to all participants to examine for presence of $\mathrm{BE}$.

\subsubsection{Eating disorder symptoms}

The Eating Disorders Examination Questionnaire (EDE-Q; (Fairburn \& Beglin, 1994) is a reliable and valid short-form, selfreport version of the EDE that has demonstrated reliability for the EDE (Peterson et al., 2007). Internal consistency of the EDE-Q in the current study was adequate $(\alpha=.83)$.

\subsubsection{Inhibitory control}

A modified version of the traditional computer-based SST (See Fig. 1) was used to measure inhibitory control. During this task, an image presented on the screen for $1,000 \mathrm{~ms}$, preceded by a $500 \mathrm{~ms}$ fixation cross. For "go" trials, participants were instructed to
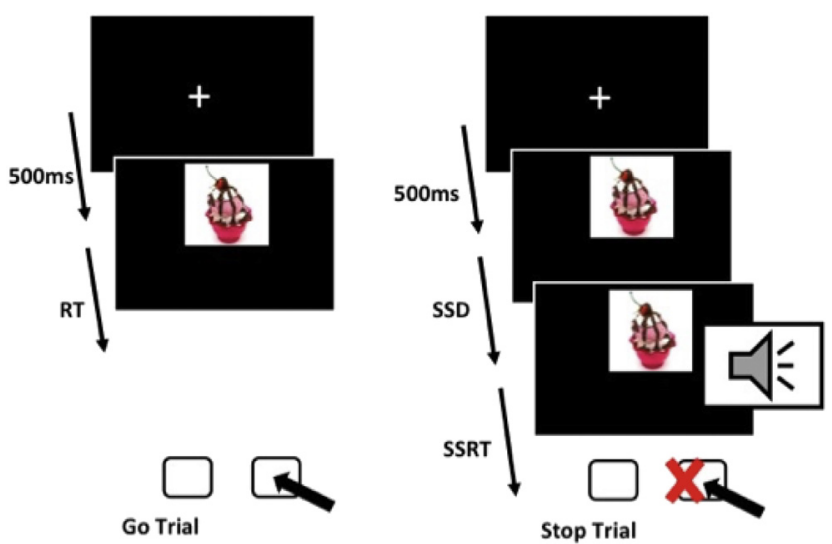

Fig. 1. Schematic of the stop signal task (SST). 
respond as fast as possible to categorize the images located on the top or bottom of the screen using left or right shift keys (i.e., left for top, right for bottom). Using top or bottom screen location is consistent with other investigations, and allowed us to 1) maintain the categorization element of the original SST (Logan, 1994); and 2) counterbalance instructions within subjects (Houben, 2011; Houben et al., 2014). The screen cleared after 1,500 ms without a response. During "stop" trials, participants were asked to inhibit responses to stimuli upon hearing a discrete $(5 \mathrm{~ms})$ auditory tone through headphones. The delay between the presented stimuli and stop signal was initially set at $250 \mathrm{~ms}$, and could not exceed $1,050 \mathrm{~ms}$. Depending on the performance, the stop signal delay was either increased or decreased by $50 \mathrm{~ms}$ such that the task becomes more or less difficult (i.e., success at inhibition will prompt a decreased interval between stop times). Using this method, each participant should be able to achieve inhibited responses on approximately $50 \%$ of all stop trials (Logan, Schachar, \& Tannock, 1997).

The task began with two practice blocks using six randomly selected neutral images (e.g., paperclips). The subsequent six test blocks consisted of 60 trials each (20 of which were "stop" trials) from a pool of six images per stimulus category (e.g., neutral, pleasant, and highly palatable foods). On average, participants rated the taste of the food stimuli to be between "fairly good" and "very good" ( $M=3.19, S D=.44$, on a 4-point Likert scale), suggesting that food the stimuli were strong enough to trigger an appetitive response. We counterbalanced for the order of task blocks, thereby controlling for order effects. Test blocks consisted of two blocks of neutral image stimuli (e.g. scissors), then two blocks of pleasant stimuli (e.g. flowers), then two blocks of highly palatable food stimuli (e.g. pizza). We reversed the stimuli block order such that the food stimuli were administered first and the neutral stimuli were administered last for approximately half of the participants.

The outcome measure used for the current study is the stop signal reaction time (SSRT). SSRT was calculated for each set of stimuli (i.e., SSRT stimulus type) for each subject by subtracting average stop signal delay from the average reaction time on "go" trials (Verbruggen \& Logan, 2008). The recording accuracy of reaction time and stop signal delay measurement was to the millisecond. A smaller SSRT is indicative of greater inhibitory control and a larger SSRT reflects poorer inhibitory control.

\subsubsection{Depressive symptoms}

The Beck Depression Inventory-II (BDI-II; (Beck, Steer, \& Brown, 1996) is a reliable and valid self-report measure of depressive symptomatology in the previous two weeks. (Dozois, Dobson, \& Ahnberg, 1998; Steer, Ball, Ranieri, \& Beck, 1997). Internal consistency in the current sample was good $(\alpha=.91)$.

\subsection{Statistical analysis}

A $2 \times 3$ (BE status by SST stimulus type) factorial analysis of covariance (ANCOVA), with SST stimulus type as the withinsubjects factor and group (BE or OWC) as the between-subjects factor, was conducted to examine main effects and interaction effects of these variables on SSRT scores. Statistical Package for the Social Sciences v. 20.0 (IBM., 2013) was used to analyze data. The BE group was younger than the OW group, thus, we included age as a covariate in analyses. We first ran the ANCOVA controlling only for age. We repeated the model with depressive symptoms (BDI-II) added as a covariate in order to examine whether differences in depressive symptoms could explain differences between groups. SSRT scores were positively skewed; thus, we conducted a square root transformation, which successfully normalized the distributions. Use of the transformed variables in analyses did not significantly alter results; thus, we report statistics using nontransformed variables. Mauchly's test of sphericity was violated in ANCOVA analyses; thus, we utilized a Greenhouse-Geisser correction to decrease the odds of Type I error.

\section{Results}

\subsection{Descriptive statistics}

Sample demographics and clinical characteristics are presented in Table 1. BMI showed non-significant associations with SST on all conditions of the task (Pearson's $r \mathrm{~s}=.06-.14, \mathrm{ps}=.31-.67$ ). Of the OWC group, $12.0 \%(n=7)$ were on a psychiatric medication, while $48 \%(n=12)$ of the BE group were on a psychiatric medication $\left(\chi^{2}=5.35, p<.01\right)$. Taking a psychiatric medication did not significantly impact SST performance $(t s=.47-.83, p s=.41-.64)$. Depressive symptoms trended towards being higher in those taking a psychiatric medication $(t=1.96, p=.05)$. Descriptive statistics of performance on the SST are included in Table 2.

\subsection{Outcome analyses}

When controlling only for age, the ANCOVA revealed a small and statistically non-significant main effect of SST stimulus type ( $F$ $\left.(1.63,142.06)=.84, p=.36, \eta_{p}^{2}=.01\right)$. Consistent with hypotheses, there was a statistically significant effect of BE status on SSRT ( $F(1$, $\left.88)=7.97, p=.003, \eta_{p}^{2}=.10\right)$. The BE status $\mathrm{x}$ SST stimulus type interaction effect was, however, negligible $(F(1.63,142.06)=.32$, $\left.p=.68, \eta_{p}^{2}<.01\right)$. When depressive symptoms were added as a covariate, results were not meaningfully changed (See Fig. 2). Specifically, the main effect of SST stimulus type was small and not statistically significant $\left(F(1.63,140.40)=1.51, p=.23, \eta_{p}^{2}=.02\right)$, the main effect of BE status on SSRT remained significant $\left(F(1,87)=5.70, p=.02, \eta_{p}^{2}=.06\right)$, and the BE status $\mathrm{x}$ SST stimulus type interaction effect remained statistically non-significant $\left(F(1.63,140.40)=.16, p=.81, \eta_{p}^{2}<.01\right)$. BDI-II as a covariate was not significant $\left(\eta_{p}^{2}<.01\right)$ in the model.

\section{Discussion}

The results of the current study partially support our initial hypotheses. As predicted, and consistent with previous research, the BE group exhibited poorer inhibitory control when compared to BMI-matched controls on all stimulus categories of the SST. This result highlights the potentially important role of inhibitory control in the development and/or maintenance of BE (Duchesne et al., 2010; Hege et al., 2015; Manasse et al., 2014; Mobbs et al., 2011; Svaldi et al., 2014b). Importantly, the deficits were observed relative to a BMI-equivalent non-BE sample, adding to the evidence base that inhibitory control is implicated specifically in the maintenance of $\mathrm{BE}$ in the context of obesity. Individuals with BE may have weaker inhibitory control, even in the absence of food stimuli, that may contribute to the development of a compelled drive (i.e., LOC) to eat that distinguishes BE episodes from general overeating episodes. More research is required to establish temporal precedence between inhibitory control deficits and onset of BE. However, extant evidence indicates directly improving inhibitory control could be an important treatment target, such as using a SST paradigm to enhance inhibitory control (Houben, 2011).

Contrary to our hypotheses, however, we did not detect a BE status $x$ SST stimulus type interaction effect, suggesting that the inhibitory control performance was equivalently impaired for BE participants across stimuli. The absence of an interaction effect between stands in conflict with a previous finding (Svaldi et al., 
Table 1

Descriptive and clinical characteristics by group.

\begin{tabular}{|c|c|c|c|c|c|}
\hline & BE group $(n=25), M(S D)$ & OWC group $(\mathrm{n}=65), \mathrm{M}(\mathrm{SD})$ & $t$ & $p$ & Cohen's $d$ \\
\hline Age (yrs) & $45.06(14.86)$ & $52.40(9.17)$ & 2.50 & .02 & .59 \\
\hline Objective binge episodes ${ }^{\mathrm{a}}$ & $11.08(9.69)$ & - & - & - & - \\
\hline Subjective binge episodes ${ }^{a}$ & $6.08(12.48)$ & - & - & - & - \\
\hline Body Mass Index $\left(\mathrm{kg} / \mathrm{m}^{2}\right)$ & $35.23(7.69)$ & $36.72(5.54)$ & .96 & .34 & .22 \\
\hline BDI-II & $17.54(10.13)$ & $8.49(7.62)$ & 4.53 & $<.01$ & 1.00 \\
\hline EDE-Q Restraint & $1.65(1.46)$ & $1.42(1.25)$ & .56 & .55 & .17 \\
\hline EDE-Q Eating Concern & $2.47(1.29)$ & $1.49(1.20)$ & 3.10 & $<.01$ & .79 \\
\hline EDE-Q Shape Concern & $3.93(1.60)$ & $3.67(1.25)$ & .96 & .34 & .18 \\
\hline EDE-Q Weight Concern & $3.72(1.23)$ & $3.27(1.02)$ & 1.59 & .12 & .40 \\
\hline EDE-Q Global Score & $2.97(1.12)$ & $2.44(.82)$ & 2.27 & $<.05$ & .54 \\
\hline
\end{tabular}

$\mathrm{BE}=$ binge eating, OWC $=$ overweight control BDI-II = Beck Depression Inventory $-\mathrm{II}, \mathrm{EDE}-\mathrm{Q}=$ Eating Disorders Examination Questionnaire

${ }^{a}$ In the past 30 days.

Table 2

Descriptive statistics regarding performance on the stop signal task (SST).

\begin{tabular}{|c|c|c|c|c|c|}
\hline & BE group $\mathrm{M}(\mathrm{SD})$ & OWC group $\mathrm{M}(\mathrm{SD})$ & $t$ & $p$ & Cohen's $d$ \\
\hline \multicolumn{6}{|l|}{ SST neutral condition } \\
\hline Stop signal delay (ms) & $618(188)$ & $678(230)$ & 1.17 & .25 & .28 \\
\hline Accuracy $^{a}$ & $.76(.08)$ & $.78(.10)$ & .93 & .36 & .02 \\
\hline Go reaction time (ms) & $914(165)$ & $909(173)$ & .12 & .90 & .03 \\
\hline Correctly inhibited $^{\mathrm{b}}$ & $.52(.06)$ & $.56(.14)$ & 1.17 & .24 & .37 \\
\hline \multicolumn{6}{|c|}{ SST positive non-food condition } \\
\hline Stop signal delay (ms) & $692(201)$ & $742(237)$ & .92 & .36 & .23 \\
\hline Accuracy $^{\mathrm{a}}$ & $.76(.07)$ & $.76(.09)$ & -.11 & .91 & .00 \\
\hline Go reaction time (ms) & $948(185)$ & $936(189)$ & .28 & .78 & .07 \\
\hline Correctly inhibited $^{\mathrm{b}}$ & $.55(.05)$ & $.53(.10)$ & .89 & .38 & .25 \\
\hline \multicolumn{6}{|l|}{ SST food condition } \\
\hline Stop signal delay (ms) & $681(242)$ & $724(224)$ & .80 & .43 & .19 \\
\hline Accuracy $^{\mathrm{a}}$ & $.72(.08)$ & $.75(.08)$ & 1.31 & .20 & .38 \\
\hline Go reaction time (ms) & 955 (177) & 925 (193) & .61 & .54 & .14 \\
\hline Correctly inhibited $^{\mathrm{b}}$ & $.52(.07)$ & $.54(.06)$ & .62 & .54 & .31 \\
\hline
\end{tabular}

a Accuracy = proportion of participant correct responses on go trials (categorization) to total go trials in block.

b Correctly inhibited = proportion of participant correct responses on stop trials (no response) to total stop trials in block.

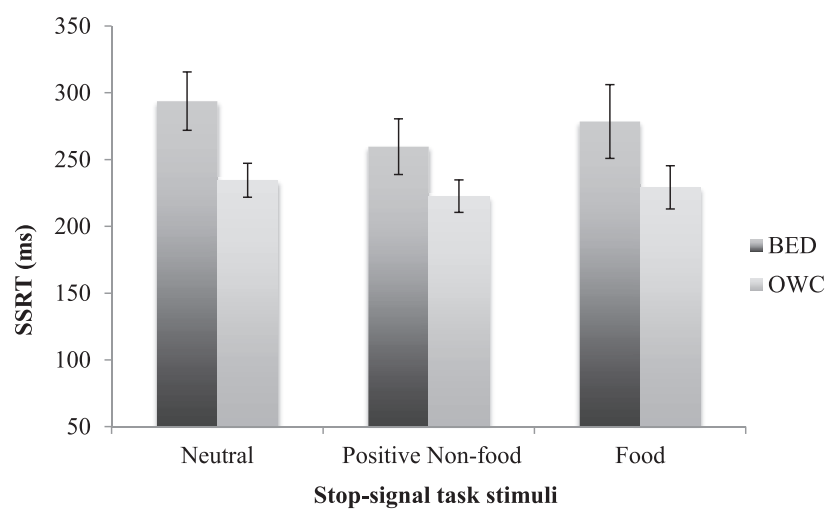

Note: Higher SSRT scores reflect poorer inhibitory control. Error bars reflect standard error of estimated marginal means.

Fig. 2. Estimated marginal means of SSRT performance by group and SSRT stimulus type, controlling for age.

2014b). However, Svaldi and colleagues used commission errors for each stimuli type as the outcome variable in the stimuli type $\times$ group interaction analysis, possibly explaining the disparate findings. We chose to use the SSRT variable because it provides a comprehensive picture of inhibitory control performance, taking into account individual differences in task difficulty adjusted based on an individual's reaction time. Thus, more consistency in outcome variables used from tasks such as the SST is necessary in order to further clarify whether inhibitory control deficits in individuals with $\mathrm{BE}$ are more pronounced when food stimuli are used.

Lastly, results indicate that deficits in inhibitory control were not mediated by the mood disturbance in the BE group. This finding appears to conflict with one study suggesting response inhibition deficits (as measured by the Stroop task) among BE individuals could be largely attributed to depressive symptoms (Manasse et al., 2015). It is possible that deficits in late-stage response inhibition (e.g., SSRT), could be specific to BE and poor conflict-monitoring (e.g., Stroop performance) could be attributable to depressive symptoms, although replication is needed to test this claim. Poor conflict monitoring might contribute to the frequent initiation of eating episodes (and association with obesity generally) whereas poor ability to inhibit an already-initiated motor response (e.g., eating), might contribute to the development of LOC over an eating episode (a unique feature of $\mathrm{BE}$ ).

Findings in this study should be considered in light of several limitations. For example, the current study featured a relatively small, all-female, overweight or obese, treatment-seeking BE sample. In addition, lack of a healthy weight control group may have precluded detecting differences in inhibitory control by stimulus type (e.g., food-specific) that could be present both in OWC and BE groups. We also did not standardize hunger state prior to the SST, which may have introduced error into the analyses (e.g., it is feasible that one group was more likely to eat prior to the assessment session). Additionally, we did not control for psychiatric diagnoses apart from depressive symptoms measured by the BDI-II. It should also be noted that we observed relatively slower reaction times in our sample compared to other studies, which could be 
attributable to a higher mean age of our sample. Finally, the SST uses visual stimuli; it could be that other types of food-related stimuli (e.g., olfactory, gustatory) may affect inhibitory control.

In sum, results from the current study support extant research reporting a relative inhibitory control deficit in overweight individuals with BE pathology. However, our hypothesis of a more pronounced inhibitory deficit in response to food stimuli was not supported. Future research will benefit from replication in order to provide directions for treatment development, particularly for enhancing weight outcomes in those with BE.

\section{Acknowledgments}

The current study was funded by a grant from the National Institutes of Digestive and Kidney Diseases awarded to Dr. Forman (R01DK095069), and two grants from the Psi Chi Honors society and the American Psychological Association of Graduate Students, awarded to Ms. Manasse.

\section{References}

Balodis, I. M., Molina, N. D., Kober, H., Worhunsky, P. D., White, M. A., Sinha, R.... Potenza, M. N. (2013). Divergent neural substrates of inhibitory control in binge eating disorder relative to other manifestations of obesity. Obesity, 21(2), 367-377.

Beck, A., Steer, R., \& Brown, G., (1996). San Antonio. TX: The Psychological Corporation.

Danaei, G., Ding, E. L., Mozaffarian, D., Taylor, B., Rehm, J., Murray, C. J. L. ... Ezzati, M. (2009). The preventable causes of death in the United States: comparative risk assessment of dietary, lifestyle, and metabolic risk factors. PLoS Medicine, 6(4), e1000058. http://dx.doi.org/10.1371/journal.pmed.1000058.

Dozois, D. J. A., Dobson, K. S., \& Ahnberg, J. L. (1998). A psychometric evaluation of the Beck Depression Inventory - II. Psychological Assessment, 10(2), 83-89. http://dx.doi.org/10.1037/1040-3590.10.2.83.

Duchesne, M., Mattos, P., Appolinário, J., de Freitas, S., Coutinho, G., Santos, C.... Coutinho, W. (2010). Assessment of executive functions in obese individuals with binge eating disorder. Revista Brasileira de Psiquiatria (São Paulo, Brazil: 1999), 32(4), 381.

Fairburn, C. G., \& Beglin, S. J. (1994). Assessment of eating disorders - interview or self-report questionnaire. International Journal of Eating Disorders, 16(4), $363-370$.

Geliebter, A., Ladell, T., Logan, M., Schweider, T., Sharafi, M., \& Hirsch, J. (2006) Responsivity to food stimuli in obese and lean binge eaters using functional MRI. Appetite, 46(1), 31-35.

Grilo, C. M., Masheb, R. M., Lozano-Blanco, C., \& Barry, D. T. (2004). Reliability of the Eating Disorder Examination in patients with binge eating disorder. International Journal of Eating Disorders, 35(1), 80-85. http://dx.doi.org/10.1002/ eat.10238.

Grucza, R. A., Przybeck, T. R., \& Cloninger, C. R. (2007). Prevalence and correlates of binge eating disorder in a community sample. Comprehensive Psychiatry, 48(2), 124-131.

Hege, M. A., Stingl, K. T., Kullmann, S., Schag, K., Giel, K. E., Zipfel, S. ... Preissl, H. (2015). Attentional impulsivity in binge eating disorder modulates response inhibition performance and frontal brain networks. International Journal of Obesity, 39(2), 353-360.

Hofmann, W., Friese, M., \& Strack, F. (2009). Impulse and self-control from a dualsystems perspective. Perspectives on Psychological Science, 4(2), 162-176.

Houben, K. (2011). Overcoming the urge to splurge: influencing eating behavior by manipulating inhibitory control. Journal of Behavior Therapy and Experimental Psychiatry, 42(3), 384-388.

Houben, K., Nederkoorn, C., \& Jansen, A. (2014). Eating on impulse: the relation between overweight and food-specific inhibitory control. Obesity, 22(5), E6-E8.

IBM. (2013). SPSS statistics for Macintosh, version 22.0. Armonk, NY: IBM Corp.

Kaiser, S., Unger, J., Kiefer, M., Markela, J., Mundt, C., \& Weisbrod, M. (2003). Executive control deficit in depression: event-related potentials in a Go/Nogo task Psychiatry Research: Neuroimaging, 122(3), 169-184.

Kelly, N. R., Bulik, C. M., \& Mazzeo, S. E. (2013). Executive functioning and behavioral impulsivity of young women who binge eat. International Journal of Eating Disorders, 46(2), 127-139.

Latner, J. D., Hildebrandt, T., Rosewall, J. K., Chisholm, A. M., \& Hayashi, K. (2007). Loss of control over eating reflects eating disturbances and general psychopathology. Behaviour Research and Therapy, 45(9), 2203-2211.

Logan, G. (1994). On the ability to inhibit thought and action: A users' guide to the stop signal paradigm.

Logan, G., Schachar, R. J., \& Tannock, R. (1997). Impulsivity and inhibitory control. Psychological Science, 8(1), 60-64.

Manasse, S. M., Forman, E. M., Ruocco, A. C., Butryn, M. L., Juarascio, A. S., \& Fitzpatrick, K. K. (2015). Do executive functioning deficits underpin binge eating disorder? A comparison of overweight women with and without binge eating pathology. International Journal of Eating Disorders, 48, 677-683.

Manasse, S. M., Juarascio, A. S., Forman, E. M., Berner, L. A., Butryn, M. L., \& Ruocco, A. C. (2014). Executive functioning in overweight individuals with and without loss-of-control eating. European Eating Disorders Review, 22(5), 373-377.

Mobbs, O., Iglesias, K., Golay, A., \& Van der Linden, M. (2011). Cognitive deficits in obese persons with and without binge eating disorder. Investigation using a mental flexibility task. Appetite, 57(1), 263-271.

Mond, J., Hay, P., Rodgers, B., Owen, C., Crosby, R., \& Mitchell, J. (2006). Use of extreme weight control behaviors with and without binge eating in a community sample: Implications for the classification of bulimic-type eating disorders. International Journal of Eating Disorders, 39(4), 294-302.

Nederkoorn, C., Coelho, J. S., Guerrieri, R., Houben, K., \& Jansen, A. (2012). Specificity of the failure to inhibit responses in overweight children. Appetite, 59(2), 409-413.

Pagoto, S., Bodenlos, J. S., Kantor, L., Gitkind, M., Curtin, C., \& Ma, Y. (2007). Association of major depression and binge eating disorder with weight loss in a clinical setting. Obesity, 15(11), 2557-2559. http://dx.doi.org/10.1038/ oby.2007.307.

Peterson, C. B., Crosby, R. D., Wonderlich, S. A., Joiner, T., Crow, S. J., Mitchell, J. E.... le Grange, D. (2007). Psychometric properties of the eating disorder examination-questionnaire: factor structure and internal consistency. International Journal of Eating Disorders, 40(4), 386-389. http://dx.doi.org/ $10.1002 /$ eat.20373.

Ricca, V., Mannucci, E., Moretti, S., Di Bernardo, M., Zucchi, T. Cabras, P. ... Rotella, C. (2000). Screening for binge eating disorder in obese outpatients. Comprehensive Psychiatry, 41(2), 111-115.

Smith, E., Hay, P., Campbell, L., \& Trollor, J. (2011). A review of the association between obesity and cognitive function across the lifespan: implications for novel approaches to prevention and treatment. Obesity Reviews, 12(9), 740-755.

Steer, R. A., Ball, R., Ranieri, W. F., \& Beck, A. T. (1997). Further evidence for the construct validity of the Beck Depression Inventory-II with psychiatric outpatients. Psychological Reports, 80(2), 443-446.

Svaldi, J., Naumann, E., Trentowska, M., \& Schmitz, F. (2014a). General and foodspecific inhibitory deficits in binge eating disorder. International Journal of Eating Disorders, 47(5), 534-542. http://dx.doi.org/10.1002/eat.22260.

Svaldi, J., Naumann, E., Trentowska, M., \& Schmitz, F. (2014b). General and foodspecific inhibitory deficits in binge eating disorder. International Journal of Eating Disorders, 47(5), 534-542.

Svaldi, J., Tuschen-Caffier, B., Peyk, P., \& Blechert, J. (2010). Information processing of food pictures in binge eating disorder. Appetite, 55(3), 685-694.

Telch, C. F., \& Stice, E. (1998). Psychiatric comorbidity in women with binge eating disorder: prevalence rates from a non-treatment-seeking sample. Journal of Consulting and Clinical Psychology, 66(5), 768.

van Veen, V., Cohen, J. D., Botvinick, M. M., Stenger, V. A., \& Carter, C. S. (2001). Anterior cingulate cortex, conflict monitoring, and levels of processing. Neuroimage, $14(6), 1302-1308$.

Verbruggen, F., \& Logan, G. D. (2008). Response inhibition in the stop-signal paradigm. Trends in Cognitive Sciences, 12(11), 418-424.

Wilfley, D. E., Schwartz, M. B., Spurrell, E. B., \& Fairburn, C. G. (1997). Assessing the specific psychopathology of binge eating disorder patients: interview or selfreport? Behaviour Research and Therapy, 35(12), 1151-1159.

Wilfley, D. E., Wilson, G. T., \& Agras, W. S. (2003). The clinical significance of binge eating disorder. International Journal of Eating Disorders, 34(S1), S96-S106.

Wu, M., Giel, K. E., Skunde, M., Schag, K., Rudofsky, G., Zwaan, M.... Friederich, H. C. (2013). Inhibitory control and decision making under risk in bulimia nervosa and binge-eating disorder. International Journal of Eating Disorders, 46(7), $721-728$.

Wu, M., Hartmann, M., Skunde, M., Herzog, W., \& Friederich, H.-C. (2013). Inhibitory control in bulimic-type eating disorders: a systematic review and meta-analysis. PloS One, 8(12), e83412. 